\title{
Pengembangan Pemenuhan Kebutuhan Rasa Aman dan Nyaman pada Penderita Stroke yang Menggunakan Kursi Roda : Systematic Review
}

\author{
Abdan Syakura ${ }^{a}$, Sidiq Nur Hasan ${ }^{a}$, Anggeria Oktavisa Denta ${ }^{a}$ \\ ${ }^{a}$ Politeknik Negeri Madura Indonesia, Sampang, Indonesia \\ E-mail: abdansyakuro20@gmail.com
}

\begin{abstract}
Introduction: wheelchair has a rubber seat base and a structure that does not fit the user's body posture. The purpose of this study was to determine the development of meeting the needs for safety and comfort in stroke patients who use wheelchairs. Methods: The design used a descriptive systematic review method, this research was carried out from February to April 2021. Data collection was obtained by searching using predetermined keywords, then filling in the tabulation of articles in the form of authenticity tables. Results: Rubber seat material developed using foam and cooltech, seat and back structure with added headrest, and footrest structure Conclusion: Modification of the seat material and structure of the wheelchair can increase the fulfillment of the need for safety and comfort in stroke patients who use wheelchairs so that users can feel safe and comfortable when using them.
\end{abstract}

Keywords: Stroke, wheelchair, sense of security and comfort, wheelchair base and materials

\begin{abstract}
Abstrak
Pendahuluan: Kursi roda memiliki bahan alas duduk berupa karet dan struktur yang tidak sesuai postur tubuh pengguna. Tujuan penelitian ini untuk mengetahui pengembangan pemenuhan kebutuhan rasa aman dan nyaman pada penderita stroke yang menggunakan kursi roda. Metode: Desain yang digunakan metode deskriptif Systematic review, penelitian ini dilaksanakan pada bulan Februari s.d bulan April 2021. Pengumpulan data diperoleh dengan searching menggunakan kata kunci yang telah ditentukan, selanjutnya mengisi tabulasi artikel dalam bentuk tabel keaslian. Hasil: Bahan tempat duduk karet dikembangkan menggunakan busa dan cooltech, struktur tempat duduk dan sandaran dengan menambahkan sandaran kepala, dan struktur pijakan kaki. Kesimpulan: Modifikasi bahan tempat duduk dan struktur kursi roda dapat meningkatkan pemenuhan kebutuhan rasa aman dan nyaman pada pasien stroke yang menggunakan kursi roda sehingga pengguna dapat merasa aman dan nyaman saat menggunakannya.
\end{abstract}

Kata kunci: Stroke, kursi roda, rasa aman dan nyaman, alas dan bahan kursi roda

\section{PENDAHULUAN}

Pasien stroke dengan immobilisasi akibat Stroke non-hemoragik menjadi salah satu masalah kesehatan yang menimbulkan banyak masalah bagi penderitanya dan perlu perawatan yang lama. Penderita stroke non-hemoragik melakukan aktivitasnya dengan bantuan kursi roda dan menghabiskan waktunya dengan imobilisasi di kursi roda. Aktivitas yang lama di kursi roda menyababkan 
PROFESIONAL HEALTH JOURNAL

Volume 3, No. 1, Desember 2021 (Hal. 26-33)

https://www.ojsstikesbanyuwangi.com/index.php/PHJ

pasien merasa tidak nyaman dengan bahan kursi roda yang digunakan (Wirawan, 2009). Aspek kenyaman dalam penggunaan kursi roda yang lama adalah penggunaan bahan yang mendukung kenyaman pasien stroke non-hemoragik saat menggunakannya sehingga tidak menimbulkan rasa panas pada kulit yang bersentuhan langsung (Elmawati, 2019). Penggunaan bahan kursi roda yang lebih baik bagi pasien stroke non-hemoragik harus ditekankan, karena berdasarkan fakta angka kejadian stroke di dunia semakin tinggi setiap tahun.

Data World Health Organization (WHO) menunjukkan pada tahun 2020 terdapat sebanyak 7,6 juta pasien yang mengalami stroke dan meningkat sebanyak 500.000 pasien setiap tahun, diperkirakan 125.000 orang meninggal akibat stroke (Suharto, 2020). Data WHO pada tahun 2017 menunjukkan sekitar 10,9 dari 1000 penduduk di Asia Tenggara mengalami stroke dengan pravalensi 7,71\% (Wulan \& Erlida, 2020). Kejadian stroke di Indonesia menjadi penyakit mematikan nomor 1 . Data dari Kementerian Kesehatan Republik Indonesia (Kemenkes RI) pada tahun 2020, insiden stroke di Indonesia sebesar 713.783 pasien dengan pravalensi dilaporkan sekitar 10,9\% dari total kejadian (Suharto, 2020). Kejadian stroke di Provinsi Jawa timur pada tahun 2018 sebanyak 507 pasien yang mengalami stroke (Rahayu, Handayati, \& Suhariyadi, 2020). Data di RSUD H. Slamet Martodirdjo pamekasan pada tahun 2018 menunjukkan pasien yang menderita stroke terdapat $5,55 \%$ dari total kasus/ penyakit yang ada dengan jumlah pasien stroke sebanyak 348 pasien (Gultom, Wungouw, \& Trisno, 2018).

Kursi roda sangat penting bagi pasien stroke non-hemoragik untuk mendukung kegiatan aktivitas sehari-hari. Kursi roda digunakan untuk meningkatkan kemampuan mobilitas bagi orang yang memiliki keterbatasan (Batan, 2006). Keamanan dan kenyamanan merupakan unsur yang perlu diperhatikan bagi pasien stroke yang menggunakan kursi roda salah satunya dalam penggunaan bahan alas kursi roda yang bisa membuat pasien stroke nyaman saat menggunakannya (Wirawan, 2009). Pengembangan ini dibangun atas kebutuhan pasien stroke terhadap bahan alas yang digunakan pada kursi roda untuk mencegah gangguan rasa aman dan nyaman serta meningkatkan rasa nyaman bagi pasien stroke yang imobilisasi di kursi roda (Elmawati, 2019).

Tujuan dari tinjauan sistematis ini adalah untuk mengetahui pengembangan pemenuhan kebutuhan rasa aman dan nyaman pada penderita stroke yang menggunakan kursi roda

\section{METODE}

Desain

Desain penelitian adalah suatu cara sistematis yang digunakan dalam memperoleh jawaban dari pertanyaan penelitian meliputi identifikasi masalah, rumusan hipotesis, definisi operasional, cara pengumpulan data hingga analisis data (Masturoh \& Anggita, 2018). Penelitian ini menggunakan metode penelitian deskriptif systematic review yaitu metode penelitian yang digunakan untuk mensitesis hasil dari penelitian dengan menggunakan pendekatan kuantitatif (Siswanto, 2012). Penelitian ini menggambarkan, menjelaskan, dan menguraikan keadaan hasil telaah artikel penelitian yang sudah ada dan dipublikasikan

\section{Kriteria Inklusi dan Ekslusi}

Tinjauan sistematis menggunakan kriteria inklusi dengan memilih artikel internasional maupun nasional full text yang terindeks google scholar Pubmed, Science direct, ebsco dengan menggunakan kata kunci "stroke" DAN "kursi roda" 
PROFESIONAL HEALTH JOURNAL

Volume 3, No. 1, Desember 2021 (Hal. 26-33)

https://www.ojsstikesbanyuwangi.com/index.php/PHJ

DAN “rasa aman dan nyaman" DAN “alas dan bahan kursi roda. Tanggal publikasi dibatasi untuk sepuluh tahun saat ini, mulai dari 2010 hingga 2020. Selanjutnya melaksanakan tabulasi artikel dalam bentuk tabel keaslian penelitian dan membuat review terkait dengan hasil penelitian yang telah didapat.

Strategi Pencarian

Proses analisis dan pengolahan data meliputi ekstraksi data yang dirancang dengan menggunakan kriteria utama dari tujuan penelitian ini. Komponen yang diambil adalah kepentingan, desain populasi, penelitian (ukuran sampel, karakteristik dan metode rekrutmen), intervensi yang digunakan untuk pengembangan kursi roda, hasil pengembangan, metode pengumpulan data, dan analisis hasil. Kriteria artikel yang berkaitan dengan kualitas dan validitas dievaluasi dengan fokus pada ukuran sampel, alokasi klien dan kebutuhan. Langkah-langkah dalam proses melakukan systematic review antara lain menentukan apa yang sudah saat ini atau sekarang, apa saja yang akan dikembangkan, menentukan kata kunci terkait dengan artikel yang akan dijadikan bahan penelitian, menentukan junal yang sesuai dengan kriteria inklusi, menentukan batasan artikel, memilih dan melakukan seleksi artikel yang didapat sesuai dengan kriteria inklusi, membuat tabel keaslian, menelaah hasil-hasil penelitian, dan membuat kesimpulan.

\section{HASIL}

Artikel yang digunakan dalam penelitian ini diperoleh dengan hasil pencarian menggunakan kata kunci yang sudah ditentukan, sehingga ditemukan sebanyak 38.810 artikel. Artikel yang didapatkan diseleksi tahap awal dengan Syakura, dkk., Pengembangan Kursi Roda yang Efektif dalam.... menghapus artikel duplikat dan tidak sesuai dengan kriteria dan dipatkan sebanyak 45 artikel. Hasil akhir artikel yang dipilih dan sudah melewati uji kelayakan didapatkan sebanyak 15 artikel yang dijadikan bahan dalam penelitian tentang pemenuhan rasa aman dan nyaman pada pasien stroke yang menggunakan kursi roda.

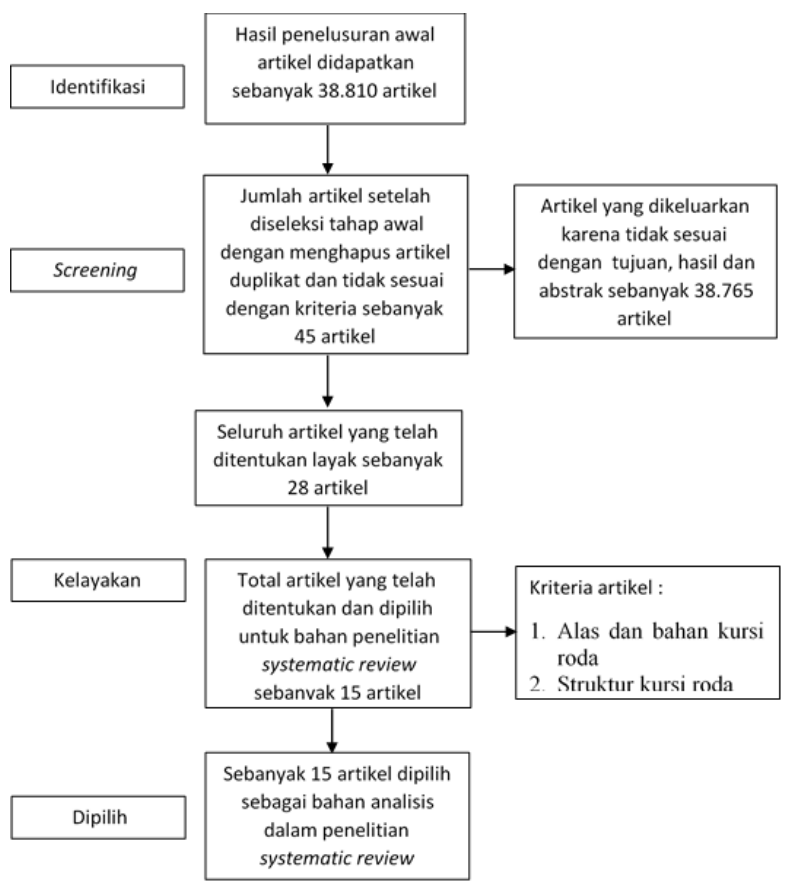

Gambar 1. Alur Penelusuran Penelitian

\section{PEMBAHASAN}

Sintesis hasil menjelaskan mengenai keinginan peneliti dalam menjawab tujuan penelitiannya dengan menelaah dan mencari jawaban dari artikel yang didapatkan. Proses penelitian literatur telah mengidentifikasi 15 artikel yang berisi bahwa bahan alas dan struktur kursi roda menjadi faktor ketidaknyamanan pasien stroke non-hemoragik saat menggunakannya. Penggunaan bahan alas dan struktur yang baik dapat meningkatkan 
PROFESIONAL HEALTH JOURNAL

Volume 3, No. 1, Desember 2021 (Hal. 26-33)

https://www.ojsstikesbanyuwangi.com/index.php/PHJ

kenyamanan dan keamanan bagi pasien stroke non-hemoragik saat menggunakan kursi roda.

Pasien memerlukan terapi untuk meningkatkan kemampuan (Syakura \& Sw, 2020) sehingga dapat hidup mandiri, sehingga perlu alat untuk membantu meningkatkan mobilitas seperti kursi roda sebagai fasilitas alat kesehatan bagi pasien stroke. Kursi roda banyak digunakan pasien stroke dalam melakukan aktivitas sehari-hari, kursi roda yang dipakai pasien stroke saat ini merupakan kursi roda konvensional yang masih menggunakan bahan duduk dan sandaran berupa karet/kalep yang tidak dapat menyerap panas dan sirkulasi udara yang masuk sedikit sehingga menimbulkan rasa panas pada kulit yang bersentuhan langsung, (Maukar, Ismanto, \& Kundre, 2014) menjelaskan, semakin tinggi tingkat kekakuan bantalan maka semakin tinggi tekanan geser antarmuka saat menggunakan kursi roda. Semakin rendah tingkat kekakuan bantalan kursi roda yang digunakan, maka semakin rendah tekanan geser antarmuka saat menggunakan kursi roda. Hasil penelitian (Jatmiko \& Dharmastiti, 2018), bahan duduk dan sandaran kursi roda perlu pengembangan dengan menggunakan bahan yang lebih baik sehingga dapat mengatur panas dan sirkulasi udara yang masuk lebih banyak. Bahan yang perlu dikembangkan berupa busa dengan tambahan cooltech yang dapat mengatur panas dan sirkulasi udara yang masuk lebih banyak. Alas dan sandaran kursi roda yang banyak digunakan pasien stroke saat ini tidak dapat menyesuaikan dengan fisiologis tubuh karena alas duduk dan sandaran kursi roda dirancang secara menggantung dan ketika digunakan posisi tubuh tidak sejajar. Kursi roda yang umum digunakan masyarakat memiliki permasalahan tidak dapat duduk dalam posisi sempurna sehingga membuat kebutuhan akan kursi roda khusus pasien tertentu tidak boleh disama ratakan dengan kursi roda umum (Kharisma \& Indrojarwo, 2017). Kursi roda dengan pengembangan bahan duduk yang lebih baik yang dapat menyerap panasa sangat dibutuhkan oleh banyak pengguna. Kursi roda dengan modifikasi cooltech dapat menjadi kursi roda yang dapat memnuhi kebutuhan pengguna dan dapat meminimalisir keluhan-keluhan yang dirasakan.

Ukuran tempat duduk dan sandaran pada umumnya kursi roda menggunakan ukuran standar sehingga tidak bisa digunakan banyak orang karena katidaksesuaian ukuran dan postur tubuh pengguna yang tidak sama, dalam hal ini didukung oleh teori (Jatmiko \& Dharmastiti, 2018), Dimensi kursi roda yang masih kurang memuaskan diantaranya: ukuran duduk kursi roda 40 $\mathrm{cm}$ x $40 \mathrm{~cm}$, ukuran sandaran kursi roda 40 $\mathrm{cm} \times 40 \mathrm{~cm}$. Alas duduk dan sandaran kursi roda harus dimodifikasi agar saat digunakan bisa menyesuikan dengan fisiologis tubuh. Alas dan sandaran kursi roda dimodifikasi agar panjang, lebar, dan tinggi bisa diatur secara manual menyesesuaikan dengan pasien yang menggunakannya. Tempat duduk dan sandaran dimodifikasi dapat diatur secara manual agar pengguna dapat leluasa mengatur lebar dan tinggi tempat duduk dan sandaran sesuai dengan keinginan pengguna kursi roda. Modifikasi sandaran dengan memberikan pembatas sandaran berupa busa dengan ketebalan $10 \mathrm{~cm}$ dibagian samping kanan dan kiri dapat meminimalisir terjatuhnya badan pasien ke kanan dan ke kiri.

Kursi roda yang digunakan pada umumnya tidak memiliki sandaran kepala sehingga pengguna merasa tidak aman saat bersandar dan berisiko kepala terjengkal ke belakang. Mempertahankan rasa aman dan keselamatan merupakan tindakan menghindari ancaman yang dapat berupa penyakit, kecelakaan, bahaya, atau 
PROFESIONAL HEALTH JOURNAL

Volume 3, No. 1, Desember 2021 (Hal. 26-33)

https://www.ojsstikesbanyuwangi.com/index.php/PHJ

pemajanan pada lingkungan dengan menghindari ancaman yang mengancam tubuh (Kasiati, 2012). Kursi roda harus ditambah sandaran kepala berupa busa yang dirancang untuk bisa dilepas saat tidak akan digunakan dan bisa dipasang saat akan digunakan. perancangan sandaran kepala dapat meminimalisir bahaya terjengkalnya kepala ke belakang saat menggunakan kursi roda, juga dapat memberikan rasa nyaman sat digunakan karena sandaran kepela dapat mengatur posisi kepala saat menggunakan kursi roda. Penambahan sandaran kepala dapat melindungi kepala jatuh ke samping.

Struktur pijakan kaki yang digunakan kursi roda konvensional tidak memberikan kesesuaian dengan tinggi badan pengguna, pengguna yang memiliki badan tinggi atau pendek cenderung tidak sama dengan tinggi pijakan kaki, dalam hal ini didukung oleh teori (Sprigle, 2014), Permukaan dan kaki harus didukung penuh dengan cukup, pijakan kaki terlalu tinggi mengakibatkan paha terangkat dari permukaan kursi sehingga mengakibatkan peningkatan tekanan pada jaringan bokong. Sebaliknya, pijakan kaki yang terlalu rendah mengakibatkan dukungan kaki yang buruk. Modifikasi pijakan kaki perlu dilakukan agar pijakan kaki dapat disesuaikan secara manual dengan tinggi kaki penggunanya. Pijakan kaki dimodifikasi untuk memberikan kenyamanan bagi pengguna, pijakan kaki dibuat menjadi sejajar dengan tubuh pasien, pijakan kaki juga dimodifikasi sistem ketinggiannya untuk menyesuaikan dengan pengguna. Ketinggian pijakan dapat diatur secara manual untuk meminimalisir tekanan saat duduk sehingga dapat menurunkan tekanan pada jaringan kulit yang imobilisasi lama di kursi roda. Pengembangan struktur pijakan kaki dengan memberikan sudut yang bermacam-macam mulai dari $90^{\circ}$ sampai $180^{\circ}$ dengan tambahan sandaran pada bagian belakang betis pasien.
Hasil penelitian menunjukkan pasien stroke non-hemoragik memerlukan terapi untuk meningkatkan kemampuan sehingga dapat hidup mandiri, sehingga perlu alat untuk membantu meningkatkan mobilitas seperti kursi roda sebagai fasilitas alat kesehatan bagi pasien stroke nonhemoragik. Kursi roda yang dipakai pasien stroke non-hemoragik saat ini merupakan kursi roda konvensional yang masih menggunakan bahan duduk dan sandaran berupa karet/kalep yang tidak dapat menyerap panas dan sirkulasi udara yang masuk sedikit sehingga menimbulkan rasa panas pada kulit yang bersentuhan langsung. Pengembangan kursi roda agar dapat meningkatkan pemenuhan kebutuhan rasa aman dan nyaman bagi pengguna. Pengembangan kursi roda meliputi bahan duduk dan struktur kursi roda. Pengembangan bahan duduk kursi roda dapat memberikan rasa nyaman saat digunakan karena dapat mengatur panas dan sirkulasi udara yang masuk lebih banyak. Pengembangan struktur kursi roda dapat memberikan modifikasi struktur tempat duduk dapat digunakan pengguna dengan berbagai postur tubuh, kepala tidak terjengkal ke belakang dengan adanya sandaran kepala, dan dapat mengatur ketinggian pijakan kaki sesuai dengan yang diinginkan. Memberikan rasa aman dan keselamatan merupakan tindakan menghindari ancaman yang dapat berupa penyakit, kecelakaan, bahaya, atau pemajanan pada lingkungan dengan menghindari ancaman yang mengancam tubuh (Kasiati, 2012).

Mengenai bahwa strategi pencarian diimplementasikan dalam konteks yang luas pada tahap awal, studi tinjauan ini memiliki beberapa keterbatasan. Keterbatasan dalam penelitian ini sumber pengumpulan data yang menggunakan artikel kurang efisien karena hanya terbatas pada google scholar, sehingga hasilnya kurang maksimal dalam menemukan 


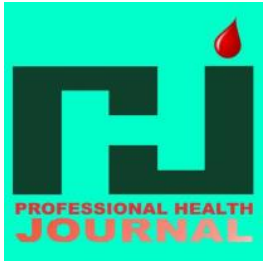

artikel yang sesuai dengan keyword yang diinginkan. Artikel yang telah ditelaah hanya berupa perancangan pengembangan pada kursi roda tanpa adanya uji kelayakan.

\section{KESIMPULAN DAN SARAN}

Pengembangan kursi roda yang bertujuan mengembangankan pemenuhan kebutuhan rasa aman dan nyaman pada penderita stroke yang menggunakan kursi roda meliputi bahan duduk kursi roda menggunakan busa dan cooltech, pengaturan duduk dan sandaran kursi roda, penambahan sandaran kepala, dan pengaturan ketinggian serta kemiringan sudut pijakan kaki

\section{DAFTAR PUSTAKA}

Andrijanto, A., \& Hutapea, B. P. (2019). Penentuan Data Anthropometri untuk Perancangan Ulang Produk Dengan Meninjau Interaksi Pengguna Studi Kasus Perancangan Ulang Kursi Roda ISO 7176 Untuk Anak-Anak Tuna Daksa. Journal of Integrated System, 2(1), 98-111. https://doi.org/10.28932/jis.v2i1.1721

Ardhi, N. F. P., \& I, B. M. L. (2018).

Perancangan Multipurpose Wheelchair. Rotor, 11(2), 39. https://doi.org/10.19184/rotor.v11i2.9 342

Batan, I. M. L. (2006). Pengembangan Kursi Roda Sebagai Upaya Peningkatan Ruang Gerak Penderita Cacat Kaki. Pengembangan Kursi Roda Sebagai Upaya Peningkatan Ruang Gerak Penderita Cacat Kaki, 8(2), 97-105.

https://doi.org/10.9744/jti.8.2.pp.97105

Dolan, M. J., \& Henderson, G. I. (2014).
PROFESIONAL HEALTH JOURNAL

Volume 3, No. 1, Desember 2021 (Hal. 26-33)

https://www.ojsstikesbanyuwangi.com/index.php/PHJ
Patient and equipment profile for wheelchair seating clinic provision. Disability and Rehabilitation: Assistive Technology, 9(2), 136-143. https://doi.org/10.3109/17483107.201 3.807441

Elmawati, C. (2019). Hubungan peran keluarga dengan pencegahan decubitus pada pasien stroke di ruang rawat inap RSUD Muntilan Kabupaten Magelang.

Gultom, R. D., Wungouw, H. P. L., \& Trisno, I. (2018). Hubungan Kadar Glukosa Darah dan Lokasi Lesi dengan Tingkat Defisit Neurologis Pada Pasien Stroke Iskemik. Cendana Medical Journal, 18(3), 342-350.

Gumasing, M. J. J., Villapando, A. C., \& Pernia, K. C. (2019). An ergonomic design of wheelchair bed transfer for post stroke patients. $A C M$ International Conference Proceeding Series, (June), 275-279. https://doi.org/10.1145/3335550.3339 900

Hollington, J., Hillman, S. J., TorresSánchez, C., Boeckx, J., \& Crossan, N. (2014). ISO 16840-2:2007 load deflection and hysteresis measurements for a sample of wheelchair seating cushions. Medical Engineering and Physics, 36(4), 509515.

https://doi.org/10.1016/j.medengphy.2 013.10.010

Inskip, J. A., Ravensbergen, H. J. C., Sahota, I. S., Zawadzki, C., McPhail, L. T., Borisoff, J. F., \& Claydon, V. E. (2017). Dynamic wheelchair seating positions impact cardiovascular function after spinal cord injury. PLoS ONE, 12(6), 1-16. https://doi.org/10.1371/journal.pone.0 


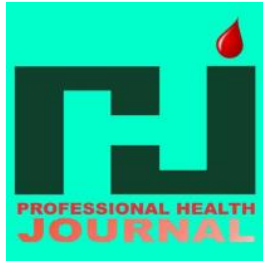

180195

Jatmiko, H. A., \& Dharmastiti, R. (2018). Pengembangan Alat Ukur Evaluasi Dan Perancangan Produk Kursi Roda. Jurnal Teknosains, 7(2), 104. https://doi.org/10.22146/teknosains.28 222

Kasiati, N. W. D. R. (2012).

KEBUTUHAN DASAR MANUSIA

I. Pusdik SDM Kesehatan, 66, 37-39.

Kharisma, A., \& Indrojarwo, B. T. (2017). Desain Kursi Roda dengan Sistem Kemudi Tuas sebagai Sarana Mobilitas bagi Anak Penderita Cerebral Palsy Usia 6 hingga 10th. Jurnal Sains Dan Seni ITS, 5(2), 271275.

Mardiana, D. P., Pujianto, M. R., \& Sulistyo. (2019). Perancangan Kursi Roda Ergonomis Untuk Orang Manula, 1(1), 11-17.

Masturoh, I., \& Anggita, N. (2018). METODOLOGI PENELITIAN KESEHATAN. BAHAN AJAR REKAM MEDIS DAN INFORMASI KESEHATAN (RMIK), 7(2), 1-16.

Maukar, M., Ismanto, A., \& Kundre, R. (2014). Hubungan Pola Makan Dengan Kejadian Stroke Non Hemoragik Di Irina F Neurologi Rsup. Prof. Dr. R. D. Kandou Manado. Jurnal Keperawatan UNSRAT, 2(2), 107000.

Mulyadi. (2016). Pengujian Prototipe Multipurpose Wheelchair. Rekayasa Energi Manufaktur, 1(1). https://doi.org/10.21070/r.e.m.v1i1.17 1

Rahayu, P. N., Handayati, A., \& Suhariyadi. (2020). HUBUNGAN KADAR GULA DARAH PUASA
PROFESIONAL HEALTH JOURNAL

Volume 3, No. 1, Desember 2021 (Hal. 26-33) https://www.ojsstikesbanyuwangi.com/index.php/PHJ

DAN PROFIL LIPID PADA PENDERITA DIABETES MELITUS TIPE 2 DENGAN KEJADIAN STROKE ISKEMIK DI RSUD R.A BASOENI MOJOKERTO. Jurnal Biosains Pascasarjana, 22(2), 50-62.

Siswanto, S. (2012). Systematic Review Sebagai Metode Penelitian Untuk Mensintesis Hasil-Hasil Penelitian (Sebuah Pengantar). Buletin Penelitian Sistem Kesehatan, 13(4). https://doi.org/10.22435/bpsk.v13i4

Soewardi, H., \& Afgani, M. K. A. (2019). Innovative Design of Ergonomic Wheelchair for Disabled People. IOP Conference Series: Materials Science and Engineering, 598(1). https://doi.org/10.1088/1757899X/598/1/012033

Sprigle, S. (2014). Measure it: Proper wheelchair fit is key to ensuring function while protecting skin integrity. Advances in Skin and Wound Care, 27(12), 561-572. https://doi.org/10.1097/01.ASW.0000 456446.43330 .70

Suharto, dewi nurfiana. (2020). PENERAPAN SWEDISH

MASSASE DENGAN MENGGUNAKAN MINYAK ZAITUN TERHADAP RISIKO KERUSAKAN INTEGRITAS KULIT PADA ASUHAN KEPERAWATAN PASIEN DENGAN KASUS STROKE. Jurnal Ilmu Kesehatan, 14(2), 134-140.

Syakura, A., \& Sw, A. (2020). Self-care Management to Prevent Exacerbation for Patients with Chronic Obstructive Pulmonary Disease ( COPD ): A Systematic Review, 3(3), 391-401. https://doi.org/10.35654/ijnhs.v3i3.22 8 


\section{PROFESIONAL HEALTH JOURNAL}

Volume 3, No. 1, Desember 2021 (Hal. 26-33)

https://www.ojsstikesbanyuwangi.com/index.php/PHJ

Wirawan, R. P. (2009). Rehabilitasi Stroke pada Pelayanan Kesehatan Primer.

Wulan, D. R., \& Erlida, B. A. (2020). THE EFFECT OF NIHSS CLINICAL SCORE OUTPUT TOWARD DELIRIUM INCIDENT ON STROKE PATIENT. Journal of Nursing Invention, 1(1), 23-31.
Yudiantyo, W. (2020). Perancangan Ergonomis Pegangan Pendorong Kursi Roda Untuk Meninimasi Kesakitan Pergelangan Tangan. Journal of Integrated System, 3(1), 40-48.

https://doi.org/10.28932/jis.v3i1.2489 